\title{
Evaluation of Laboratory Formulated Hand Sanitizing Gel in Riyadh Municipality Central Area Labs
} \author{
Abdullah Sulaiman Alrebay ${ }^{4}$ \\ ${ }^{1}$ Head Microbiology Section, Riyadh Municipality Central Area Labs, Riyadh, KSA \\ ${ }^{2}$ Chemistry Section, Riyadh Municipality Central Area Labs, Riyadh, KSA \\ ${ }^{3}$ Deputy of Riyadh Municipality for Services, Riyadh, KSA \\ ${ }^{4}$ Manager, General Directorate of Environmental Health, Riyadh, KSA
}

Mir Naiman $\mathrm{Ali}^{1 *}$, Nour Guesmi ${ }^{2}$, Sowfer $\mathrm{Ali}^{1}$, Mostafa Abofard ${ }^{2}$, Mohammed Gaber ${ }^{2}$, Falah Bin Abdullah Al-Dosari ${ }^{3}$,

\begin{abstract}
DOI: $\underline{10.36348 / \text { sjmps.2020.v06i08.006 }}$
| Received: 10.08.2020 | Accepted: 18.08.2020 | Published: 26.08.2020

*Corresponding author: Mir Naiman Ali
\end{abstract}

\section{Abstract}

Currently, maintaining good hygiene and sanitization as a precautionary measure is of importance to avoid the spread of the novel Coronavirus. As a part of prophylaxis during the COVID pandemic, hand sanitizing gel was formulated in Riyadh Municipality Central Area Laboratories based on WHO guidelines. The gel was evaluated by physical, chemical and microbiological testing and compared with five commercially available hand sanitizers in Riyadh City. The results revealed that the laboratory formulated gel has a $\mathrm{pH}$ of 6.0 and $80 \%$ ethanol vlv, with very strong antibacterial activity recorded in the range of 20.1 to $21.2 \mathrm{~mm}$ against five selected bacterial strains with highest activity against E.coli ATCC 25922. The minimum inhibitory and minimum bactericidal concentration was observed to be $12.5 \%$ and the gel was able to kill the bacterial flora on volunteers hand by a Mean cfu reduction of $99.24 \%$ in 30 seconds. The results obtained in this study demonstrate that laboratory formulated gel is highly effective than 5 commercial brands against all the bacterial strains tested.

Keywords: Ethanol, Efficacy, MIC, MBC, Hand sanitizer.

Copyright @ 2020: This is an open-access article distributed under the terms of the Creative Commons Attribution license which permits unrestricted use, distribution, and reproduction in any medium for non-commercial use (NonCommercial, or CC-BY-NC) provided the original author and source are credited.

\section{INTRODUCTION}

Alcohol based hand sanitizers are widely used for hand antisepsis [1]. According to WHO alcohol based hand rub is an alcohol containing preparation (liquid, gel or foam) designed for application to the hands to inactivate microorganisms and/or temporarily suppress their growth. Such preparation may contain one or more type of alcohol, other active ingredients with excipients and humectants [2]. The other active ingredients are quaternary ammonium compounds, triclosan, chlorhexidine, chloroxylenol, hexachlorophene and iodine and iodophores that mainly contribute to efficacy of formulations [3].

The antimicrobial activity of alcohols is due to their denaturing ability of proteins. $60-80 \%$ alcohol solutions are most effective, with higher concentrations being less effective as proteins are not denatured easily in the absence of water [4]. Alcohols have excellent in vitro germicidal activity against Gram-positive and Gram-negative vegetative bacteria (including MRSA and VRE), M.tuberculosis, and a variety of fungi [5-7].
However, they have virtually no activity against bacterial spores or protozoan oocysts, and very poor activity against some non-enveloped (non-lipophilic) viruses. Some enveloped (lipophilic) viruses such as herpes simplex virus (HSV), HIV, influenza virus, $\mathrm{RSV}$, and vaccinia virus are susceptible to alcohols when tested in vitro [8].

A novel coronavirus (SARS-CoV-2) has recently emerged from Wuhan city of China $\left(30^{\text {th }}\right.$ December 2019) with a total of 153,517 confirmed cases and 5735 reported deaths (as of March 15, 2020) [9]. WHO has characterized COVID-19 as pandemic on $11^{\text {th }}$ of March 2020. As per Centers for Disease Control and Prevention (CDC) this virus mainly spreads from person-to-person, between people who are in close contact with one another (within about 6 feet), and through respiratory droplets produced when infected person coughs or sneezes. These droplets can land in mouths or noses of people who are nearby or possibly be inhaled into the lungs [10]. There is currently no vaccine to prevent coronavirus disease 2019 (COVID19).The best way to prevent illness is to avoid being 
Naiman Ali et al., Saudi J Med Pharm Sci, August, 2020; 6(8): 548-558

exposed to this virus. Wash your hand with soap and water and hand sanitizer that contains at least $60 \%$ alcohol.

The bacteria that are recovered from the hands are divided into two categories- resident or transient [11]. The resident flora consists of microorganisms that are residing under the superficial cells of the stratum corneum and can also be found on the surface of the skin [12]. Resident flora has two main protective functions: microbial antagonism and the competition for nutrients in the ecosystem. Transient flora colonizes the superficial layers of the skin and is more amenable to removal by routine hand hygiene. Transient microorganisms do not usually multiply on the skin, but they survive and sporadically multiply on skin surface [13]. They are often acquired by HCWs (health care workers) during direct contact with patients or contaminated environmental surfaces adjacent to the patient and are the organisms most frequently associated with HCAIs (health care associated infections).

Keeping in view the importance of hand sanitizer and shortage in market supply due to COVID19 pandemic, Riyadh Municipality Central Area Labs has taken the efforts to formulate their own product and produced the hand sanitizing gel in laboratory. The objective of this study was to evaluate the formulated gel by physical, chemical properties and antibacterial efficacy tests.

\section{Methodology}

The laboratory formulated gel prepared in Riyadh Municipality Central Area Labs was tested for physical, chemical and microbiological analysis including efficacy studies. The analysis was compared with 5 commercially available hand sanitizing gels in Riyadh, Saudi Arabia.

\section{Physical Analysis}

$\mathrm{pH}$ of the gel was tested by a pre-calibrated $\mathrm{pH}$ meter (Mettler Toldeo, Philippines). Color, and homogeneity were observed visually and odor was also recorded.

\section{Chemical Analysis}

The ready to use gel after formulation was tested for percentage of ethanol as active ingredient by GC-Head Space (Agilant, California, United States).

\section{Microbiological Analysis \\ Antibacterial activity by Agar well diffusion Assay \\ A total of five bacterial species- two gram positive Staphylococcus aureus ATCC 6538, and Enterococcus faecalis ATCC 33186 and three gram negative bacteria Escherichia coli ATCC 25922, Pseudomonas aeruginosa ATCC 9027, and Salmonella typhi ATCC 14028 from American Type Culture}

Collection Centre were tested for antibacterial efficacy. The cultures were maintained on tryptone soya agar (Oxoid, UK) at $4^{0} \mathrm{C}$. Inoculum for testing was prepared as per CLSI M02-A12 [14]. For preparation of inoculum, isolated colonies of each bacterial culture were selected from 18-24 hours incubated agar plates and inoculated in tryptone soya broth (Oxoid, UK) to make a suspension. The turbidity of the suspension was adjusted to achieve a CFU of 1.0 to $2.0 \times 10^{8} \mathrm{CFU} / \mathrm{ml}$ (CLSI) by UV-Visible Spectrophotometer (UV 1800, Shimatzu, Switzerland) at $600 \mathrm{~nm} .0 .1 \mathrm{ml}$ of each bacterial culture suspension was inoculated on Mueller Hinton agar (Oxoid, UK) plates and evenly spread with a sterile spreader. $6 \mathrm{~mm}$ wells were cut with a sterile borer and $50 \mu \mathrm{l}$ of formulated gel and commercial brand gels were added in wells. Positive and negative controls were also run with $70 \%$ ethanol and DMSO (dimethyl sulfoxide). All plates were allowed to settle for $5 \mathrm{~min}$ and incubated at $37^{\circ} \mathrm{C}$ for $18-24$ hours. After incubation, inhibition zones surrounding the wells produced by each sanitizing gel were recorded on an automatic colony counter under inhibition zone mode (Scan 1200, Interscience, France).

\section{Efficacy Studies}

The formulated hand sanitizer gel and 5 commercial brands of hand sanitizers were tested for efficacy by 3 methods:

a) Determination of MIC, b) Determination of MBC and c) Hygienic Hand Rub Test on volunteers.

\section{Determination of Minimal Inhibitory Concentration (MIC)}

MIC was determined by Macrodilution method in sterile test tubes as per CLSI 07-08 [15]. The laboratory formulated gel ready to use was diluted in Mueller Hinton broth (Oxoid, UK) in such a way that at every step there is a $1: 2$ dilution and a series of concentrations from $100 \%, 50,25,12.25,6.25,3.12$, $1.56,0.78,0.39$ and $0.195 \%$ were prepared. Inoculum of test strains was prepared in three steps, in first step the cell suspension of each bacterial strain was prepared as mentioned in agar well diffusion assay containing 1.0-2.0 $\times 10^{8} \mathrm{CFU} / \mathrm{ml}$. In second step this suspension was diluted 1:150 to obtain a cell density of $1 \times 10^{6}$ $\mathrm{CFU} / \mathrm{ml}$. In the third step the cell suspension was further diluted 1:2 to obtain a final inoculum of $5 \times 10^{5}$ $\mathrm{CFU} / \mathrm{ml}$. Within 15 minutes of inoculum preparation, test was performed by adding $1 \mathrm{ml}$ of adjusted inoculum to each tube containing $1 \mathrm{ml}$ of hand sanitizer in dilution series and mixed. From this tube $1 \mathrm{ml}$ was pipetted and added in second tube in dilution series resulting in 1:2 dilution. Positive control was also set by adding only broth in a tube. Similarly the process was repeated till last tube containing $0.195 \%$. The MIC was also determined in a similar manner for 5 commercial brands of hand sanitizer. All tubes were incubated at $37^{\circ} \mathrm{C}$ in an incubator for 16 to 20 hours. MIC was 
determined as the lowest concentration of the hand sanitizer that completely inhibits the growth of test organism in tubes as detected by unaided eye.

\section{Determination of Minimal Bactericidal \\ Concentration (MBC) \\ MBC was determined from the tubes of MIC} experiment after incubation by inoculating $0.1 \mathrm{ml}$ of sample from each tube onto Mueller Hinton agar plates by spread plate technique. Plates were incubated at $37^{0} \mathrm{C}$ for $18-24$ hours, following incubation MBC was calculated as the lowest concentration of hand sanitizer gel that completely kills the bacterial strains tested. This was recorded by observing absence of colony formation on Mueller Hinton agar plates confirming that the concentration of sanitizer has killed the bacterial cells and they are not viable to grow on nutrient media without any antibiotic. MBC was also determined for 5 commercial brands of hand sanitizer against all five bacterial strains.

\section{Hygienic Hand Rub Test}

Efficacy test was performed by the modified method of BS EN 1500:2013 Hygenic handrub test method [16]. 10 staff members volunteered to participate in study and verbal informed consent was collected. All volunteers were healthy who have hands with healthy skin, without cuts or abrasions and with short and clean finger nails. Volunteers participated in the experiment for a period of one week to complete the test for laboratory gel and 5 commercial brands. The test was performed on transient flora of the hands. Initially swab samples were collected from the volunteer's hand including fingers and palm and they were asked to apply the sanitizing gel and rub for 30 seconds as per the standard handrub procedure of BS EN 1500:2013. After 30 seconds again swab samples were collected from each volunteer's hand. All swab samples were inoculated on tryptone soya agar plates and incubated at $37^{\circ} \mathrm{C}$ for $20-24$ hours and colonies were calculated for pre and post treatment values on an automatic colony counter (Scan 1200, Interscience, France). For colony counts the plates containing colonies in range of 14 and 330 were selected as the European Standard 1500: 2013 allows a deviation of $10 \%$ to be accepted. Colonies were counted, percentage cfu reduction was calculated and mean reduction percentage was also calculated.

\section{RESULTS}

Riyadh Municipality Central Area laboratories took an effort to formulate ethanol based hand sanitizing gel keeping in view the rapid spread of COVID-19 globally and in Saudi Arabia. The sanitizer was produced with an objective to use it as a preventive measure to avoid infection and keeping in view CDC guidelines which states that the best way to prevent illness is to avoid being exposed to this virus and wash hand with soap and water and hand sanitizer that contains atleast $60 \%$ alcohol.

\section{Gel Formulation}

The laboratory gel formulation was optimized by a series of different experimental trials on compositions (data not shown) and the composition was optimized for the final product with ingredients shown in Table-1.

\section{Physical and Chemical Analysis}

The results for physical and chemical analysis of the hand sanitizer gel are depicted in Table-2 and Figure-1.

Table-1: Composition of Alcohol Based Hand Sanitizer

\begin{tabular}{|l|l|l|}
\hline S. No & Ingredients & Quantity (\%) \\
\hline 1 & Ethanol & $80.0 \%$ \\
\hline 2 & Distilled Water & $11.0 \%$ \\
\hline 3 & Glycerin & $9.0 \%$ \\
\hline 4 & Perfume & $0.1 \%$ \\
\hline 5 & Hydrogen Peroxide $(33 \%)$ & $0.0012 \%$ \\
\hline 6 & Triethanol amine & $0.001 \%$ \\
\hline 7 & Carbapol & $0.003 \%$ \\
\hline
\end{tabular}

Table-2: Physical and Chemical Analysis of Alcohol Based Hand Sanitizer

\begin{tabular}{|l|l|l|}
\hline S. No & Parameter & Analysis \\
\hline 1 & $\mathrm{pH}$ & 6.50 \\
\hline 2 & Color & Colorless \\
\hline 3 & Appearance & Clear, gel \\
\hline 4 & Homogeneity & Homogeneous \\
\hline 5 & Odor & Lemon fragrance \\
\hline 6 & Ethanol & $80 \%$ \\
\hline
\end{tabular}




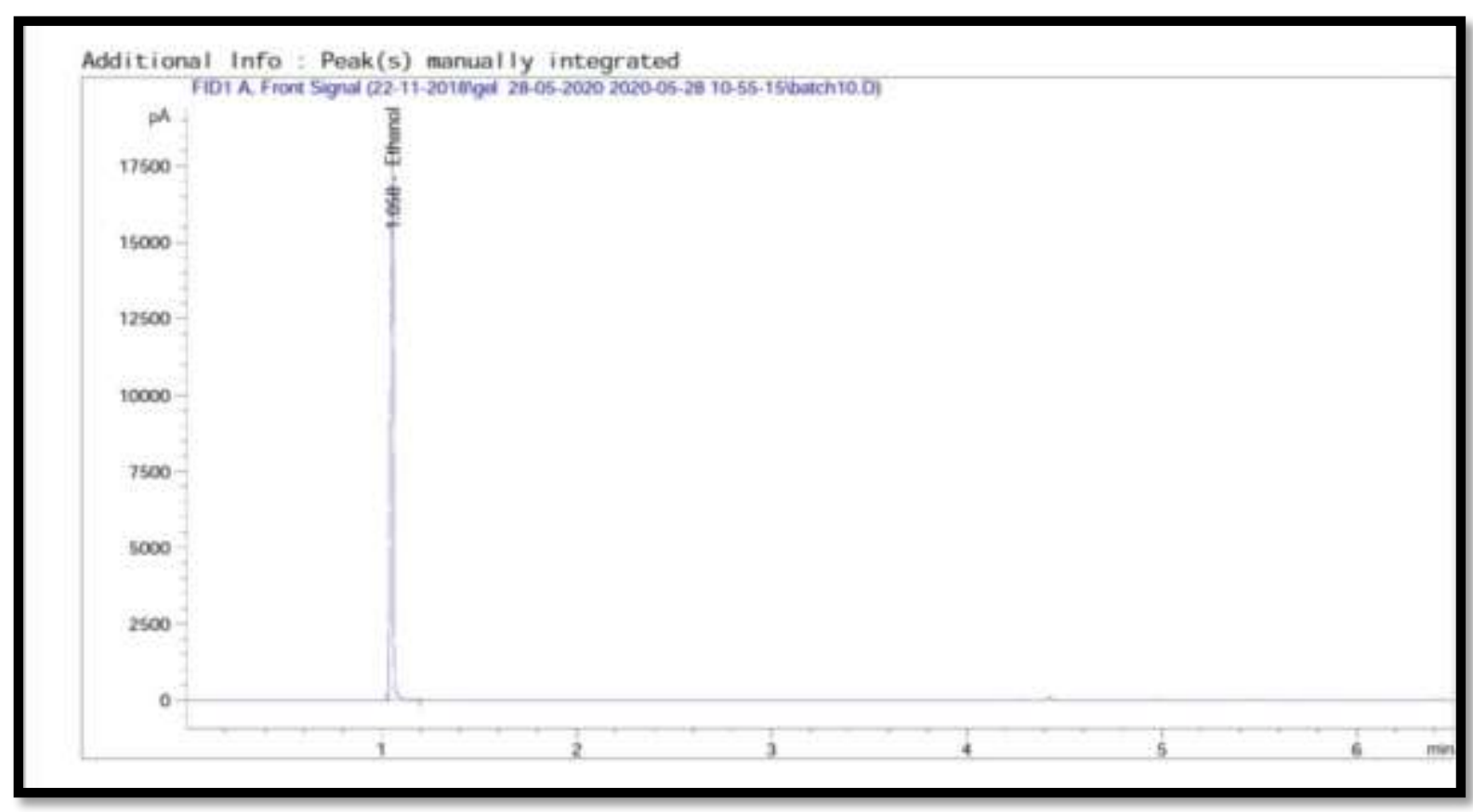

Fig-1: Gas Chromatographic Alcohol Test Report

Antibacterial activity by Agar well diffusion Assay: Antibacterial activity results for laboratory formulation and 5 commercial brands were recorded as zone of growth inhibition surrounding the well in $\mathrm{mm}$ and are shown in Table-3 and Figure-2. Comparative antibacterial activity of all commercial bands with laboratory formulation is shown in Figure-3.

\section{Efficacy Studies}

Determination of Minimal Inhibitory Concentration (MIC)

Minimal inhibitory concentration was determined by macrodilution method for the lab formulated gel and commercial brands. The results obtained are highlighted in Table-3. MIC was determined for all the 5 bacterial ATCC test strains.

\section{Determination of Minimal Bactericidal Concentration (MBC)}

Results for MBC are shown in Table-4. MBC is the lowest concentration of an antimicrobial agent which kills the bacterial stain under test and was determined by observing absence of colony formation on Mueller hinton agar plates.

\section{Hygienic Hand Rub Test}

Percentage reduction of total bacterial count of both hands of volunteers after 30 seconds of hand rub application was assessed by hand swab test and the results are shown in Table-6. Mean reduction was also calculated.

Table-3: Antibacterial Activity of Lab formulated and Commercial Hand Sanitizer Gel

\begin{tabular}{|l|l|l|l|l|l|l|}
\hline Test Organism & \multirow{2}{*}{ Lab Formulation } & \multicolumn{3}{|c|}{ Zone of Growth Inhibition in mm } \\
\cline { 3 - 7 } & & CB1 & CB2 & CB3 & CB4 & CB5 \\
\hline $\begin{array}{l}\text { E.coli } \\
\text { ATCC 25922 }\end{array}$ & $\mathbf{2 1 . 2}$ & 19.9 & 12.5 & 12.0 & 11.6 & 12.3 \\
\hline Pseudomonas aeruginosa ATCC 9027 & $\mathbf{2 0 . 1}$ & & & & & \\
\hline Staphylococcus aureus ATCC 6538 & $\mathbf{2 0 . 5}$ & 17.1 & 14.4 & 13.1 & 13.7 & 14.4 \\
\hline Enterococcus faecalis ATCC 33186 & $\mathbf{2 1 . 1}$ & 15.9 & 13.1 & 11.6 & 12.5 & 13.3 \\
\hline $\begin{array}{l}\text { Salmonella typhi } \\
\text { ATCC 14028 }\end{array}$ & $\mathbf{2 0 . 3}$ & 19.3 & 13.7 & 12.1 & 12.5 & 15.6 \\
\hline
\end{tabular}


Naiman Ali et al., Saudi J Med Pharm Sci, August, 2020; 6(8): 548-558

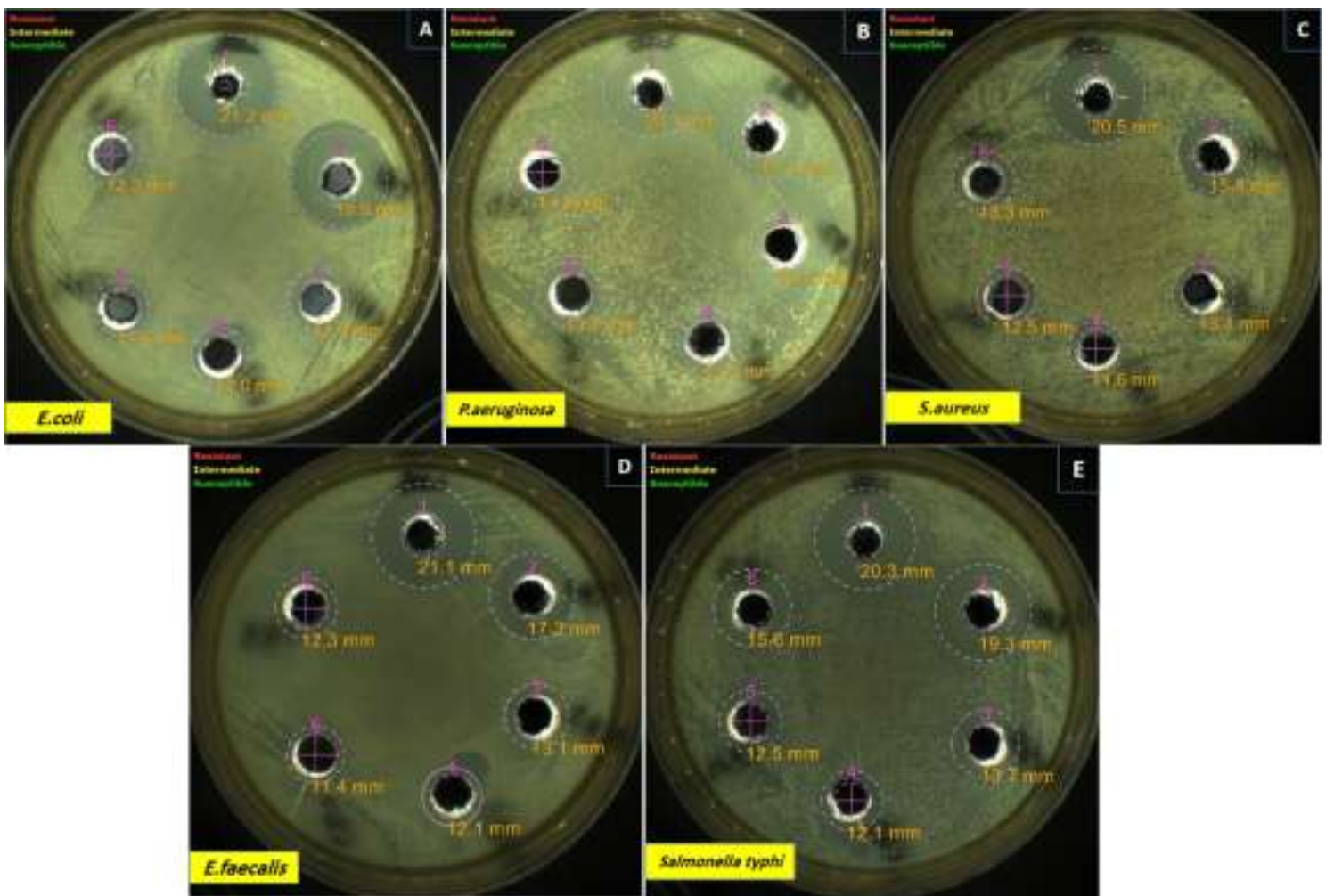

Fig-2: Inhibition Zones of Laboratory formulation and commercial brands on tested Bacterial strains [1. Laboratory formulated gel, 2. CB1, 3. CB2, 4. CB3, 5. CB4 \& 6. CB5]

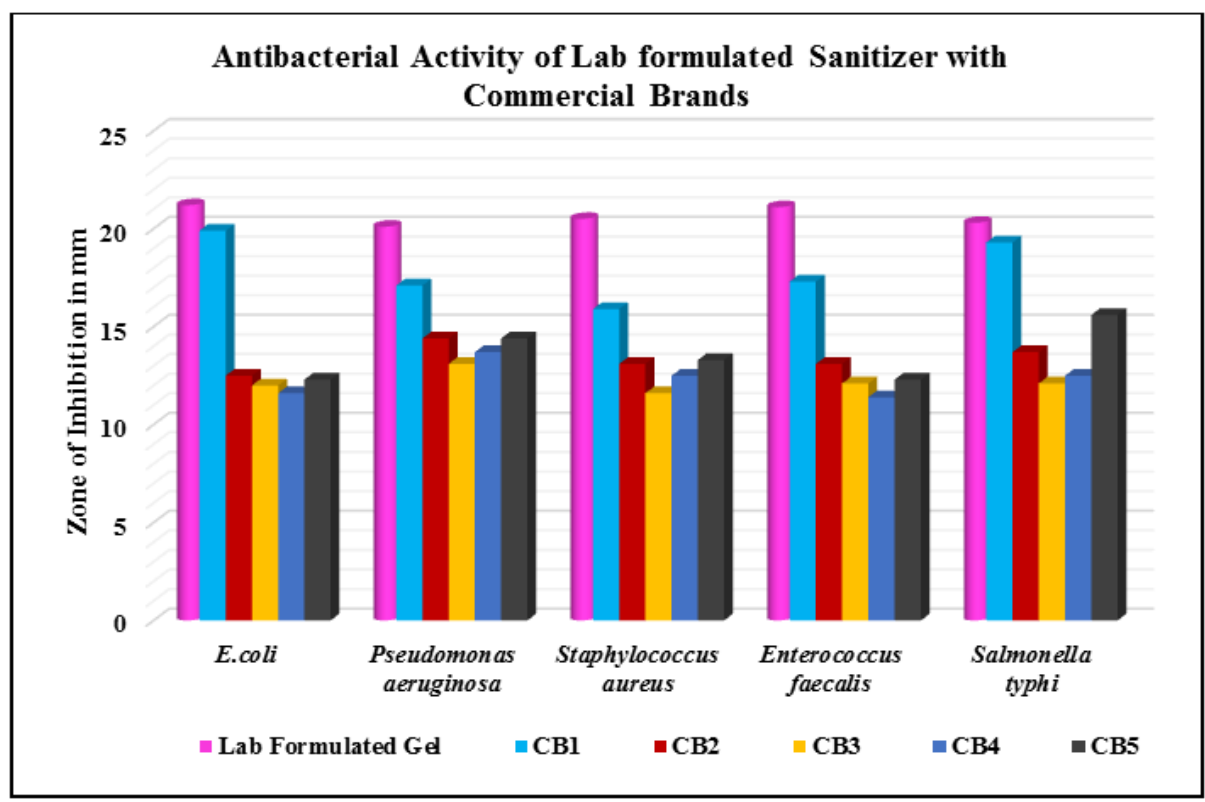

Fig-3: Comparative Analysis of Antibacterial activity of Different Commercial Brands 
Naiman Ali et al., Saudi J Med Pharm Sci, August, 2020; 6(8): 548-558

Table-4: Determination of MIC for Lab formulated Gel and Commercial Brands

\begin{tabular}{|c|c|c|c|c|c|c|}
\hline \multirow[t]{2}{*}{ Hand Sanitizer } & \multirow[t]{2}{*}{ Concentration $(\%)$} & \multicolumn{5}{|c|}{ Test Organism [- Growth Inhibition; + No Growth Inhibition] } \\
\hline & & E.coli & S.aureus & S.typhi & E.fecalis & P.aeruginosa \\
\hline \multirow{7}{*}{ Lab Formulation } & 100 & - & - & - & - & - \\
\hline & 50 & - & - & - & - & - \\
\hline & 25 & - & - & - & - & - \\
\hline & $\mathbf{1 2 . 5}$ & - & - & - & - & - \\
\hline & 6.25 & + & + & + & + & + \\
\hline & 3.125 & + & + & + & + & + \\
\hline & 1.5625 & + & + & + & + & + \\
\hline \multirow{7}{*}{ CB1 } & 100 & - & - & - & - & - \\
\hline & 50 & - & - & - & - & - \\
\hline & 25 & - & - & - & - & - \\
\hline & 12.5 & + & + & + & + & + \\
\hline & 6.25 & + & + & + & + & + \\
\hline & 3.125 & + & + & + & + & + \\
\hline & 1.5625 & + & + & + & + & + \\
\hline \multirow{7}{*}{ CB2 } & 100 & - & - & - & - & - \\
\hline & 50 & - & - & - & - & - \\
\hline & 25 & - & - & - & - & - \\
\hline & 12.5 & + & + & + & + & + \\
\hline & 6.25 & + & + & + & + & + \\
\hline & 3.125 & + & + & + & + & + \\
\hline & 1.5625 & + & + & + & + & + \\
\hline \multirow{7}{*}{ CB3 } & 100 & - & - & - & - & - \\
\hline & 50 & - & - & - & - & - \\
\hline & 25 & - & - & - & - & - \\
\hline & 12.5 & + & + & + & + & + \\
\hline & 6.25 & + & + & + & + & + \\
\hline & 3.125 & + & + & + & + & + \\
\hline & 1.5625 & + & + & + & + & + \\
\hline \multirow{7}{*}{ CB4 } & 100 & - & - & - & - & - \\
\hline & 50 & - & - & - & - & - \\
\hline & 25 & - & - & - & - & - \\
\hline & 12.5 & + & + & + & + & + \\
\hline & 6.25 & + & + & + & + & + \\
\hline & 3.125 & + & + & + & + & + \\
\hline & 1.5625 & + & + & + & + & + \\
\hline \multirow{7}{*}{ CB5 } & 100 & - & - & - & - & - \\
\hline & 50 & - & - & - & - & - \\
\hline & 25 & - & - & - & - & - \\
\hline & 12.5 & + & + & + & + & + \\
\hline & 6.25 & + & + & + & + & + \\
\hline & 3.125 & + & + & + & + & + \\
\hline & 1.5625 & + & + & + & + & + \\
\hline
\end{tabular}


Naiman Ali et al., Saudi J Med Pharm Sci, August, 2020; 6(8): 548-558

Table-5: Determination of MBC for Lab formulated Gel and Commercial Brands

\begin{tabular}{|c|c|c|c|c|c|c|}
\hline \multirow[t]{2}{*}{ Hand Sanitizer } & \multirow[t]{2}{*}{ Concentration (\%) } & \multicolumn{5}{|c|}{ Test Organism [- No Growth; + Growth; ++ Heavy Growth] } \\
\hline & & E.coli & S.aureus & S.typhi & E.fecalis & P.aeruginosa \\
\hline \multirow{7}{*}{ Lab Formulation } & 100 & - & - & - & - & - \\
\hline & 50 & - & - & - & - & - \\
\hline & 25 & - & - & - & - & - \\
\hline & $\mathbf{1 2 . 5}$ & - & - & - & - & - \\
\hline & 6.25 & ++ & ++ & - & ++ & ++ \\
\hline & 3.125 & ++ & ++ & ++ & ++ & ++ \\
\hline & 1.5625 & ++ & ++ & ++ & ++ & ++ \\
\hline \multirow{7}{*}{ CB1 } & 100 & - & - & - & - & - \\
\hline & 50 & + & + & + & + & + \\
\hline & 25 & ++ & ++ & ++ & ++ & ++ \\
\hline & 12.5 & ++ & ++ & ++ & ++ & ++ \\
\hline & 6.25 & ++ & ++ & ++ & ++ & ++ \\
\hline & 3.125 & ++ & ++ & ++ & ++ & ++ \\
\hline & 1.5625 & ++ & ++ & ++ & ++ & ++ \\
\hline \multirow{7}{*}{ CB2 } & 100 & - & - & - & - & - \\
\hline & 50 & ++ & ++ & ++ & ++ & ++ \\
\hline & 25 & ++ & ++ & ++ & ++ & ++ \\
\hline & 12.5 & ++ & ++ & ++ & ++ & ++ \\
\hline & 6.25 & ++ & ++ & ++ & ++ & ++ \\
\hline & 3.125 & ++ & ++ & ++ & ++ & ++ \\
\hline & 1.5625 & ++ & ++ & ++ & ++ & ++ \\
\hline \multirow{7}{*}{ CB3 } & 100 & - & - & + & + & - \\
\hline & 50 & ++ & ++ & ++ & ++ & ++ \\
\hline & 25 & ++ & ++ & ++ & ++ & ++ \\
\hline & 12.5 & ++ & ++ & ++ & ++ & ++ \\
\hline & 6.25 & ++ & ++ & ++ & ++ & ++ \\
\hline & 3.125 & ++ & ++ & ++ & ++ & ++ \\
\hline & 1.5625 & ++ & ++ & ++ & ++ & ++ \\
\hline \multirow{7}{*}{ CB4 } & 100 & - & - & + & + & - \\
\hline & 50 & ++ & ++ & ++ & ++ & ++ \\
\hline & 25 & ++ & ++ & ++ & ++ & ++ \\
\hline & 12.5 & ++ & ++ & ++ & ++ & ++ \\
\hline & 6.25 & ++ & ++ & ++ & ++ & ++ \\
\hline & 3.125 & ++ & ++ & ++ & ++ & ++ \\
\hline & 1.5625 & ++ & ++ & ++ & ++ & ++ \\
\hline \multirow{7}{*}{ CB5 } & 100 & - & - & - & - & - \\
\hline & 50 & ++ & ++ & ++ & ++ & ++ \\
\hline & 25 & ++ & ++ & ++ & ++ & ++ \\
\hline & 12.5 & ++ & ++ & ++ & ++ & ++ \\
\hline & 6.25 & ++ & ++ & ++ & ++ & ++ \\
\hline & 3.125 & ++ & ++ & ++ & ++ & ++ \\
\hline & 1.5625 & ++ & ++ & ++ & ++ & ++ \\
\hline
\end{tabular}

Table-6: Percentage cfu Reduction of Total Bacterial Count on Hands of Volunteers by Lab formulated Gel and Commercial Brands

\begin{tabular}{|l|l|l|l|l|l|l|}
\hline \multirow{2}{*}{ Volunteers } & \multicolumn{7}{|c|}{ Mean cfu Reduction of Total Bacterial Count of Both } \\
& \multicolumn{7}{|c|}{ Hands (\%) } \\
\cline { 2 - 7 } & $\begin{array}{l}\text { Lab } \\
\text { Formulation }\end{array}$ & CB1 & CB2 & CB3 & CB4 & CB5 \\
\hline $\mathbf{1}$ & 97.575 & 100 & 93.875 & 73.2 & 70.3 & 93.05 \\
\hline $\mathbf{2}$ & 100 & 100 & 95.55 & 81.95 & 91.9 & 97.55 \\
\hline $\mathbf{3}$ & 100 & 100 & 93.25 & 65.25 & 100 & 87.5 \\
\hline $\mathbf{4}$ & 99.4 & 92.8 & 96.6 & 92.45 & 99.3 & 100 \\
\hline $\mathbf{5}$ & 99.25 & 99.75 & 98.65 & 98.13 & 93.5 & 94.95 \\
\hline $\mathbf{6}$ & 97.575 & 100 & 93.9 & 81.9 & 70.3 & 100 \\
\hline $\mathbf{7}$ & 100 & 100 & 94.86 & 65.25 & 91.9 & 87.5 \\
\hline $\mathbf{8}$ & 100 & 100 & 95.125 & 91.6 & 100 & 97.55 \\
\hline $\mathbf{9}$ & 99.4 & 92.8 & 99.35 & 98.63 & 99.3 & 93.05 \\
\hline $\mathbf{1 0}$ & 99.23 & 98.37 & 93.63 & 73.2 & 93.5 & 94.95 \\
\hline $\begin{array}{l}\text { Mean } \\
\text { Reduction }\end{array}$ & $\mathbf{9 9 . 2 4 3}$ & $\mathbf{9 8 . 3 7 2}$ & $\mathbf{9 5 . 4 7 9}$ & $\mathbf{8 3 . 1 5}$ & $\mathbf{9 1}$ & $\mathbf{9 4 . 6 1}$ \\
\hline
\end{tabular}




\section{DISCUSSION}

The ethanol based sanitizing gel was formulated based on WHO guidelines for handrub formulations with $80 \%$ ethanol as active ingredient [17]. In 1994, the FDA Tentative Final Monograph (TFM) classified ethanol $60-95 \%$ as a generally safe and effective active agent for use in antiseptic hand hygiene or healthcare workers hand wash products [18]. Although the TFM considered that there were insufficient data to classify isopropanol $70-91.3 \%$ as effective, $60 \%$ isopropanol has subsequently been adopted in Europe as the reference standard against which alcohol-based handrub products are compared [19]. The other ingredients added in the gel were glycerin, triethanol amine, carbapol and perfume (Table-1). Additionally hydrogen peroxide was also included as one of the ingredient with an aim to kill bacterial spores and viruses as ethanol is ineffective to kill bacterial spores and some non-enveloped viruses [20]. Hydrogen peroxide has microbicidal activity against wide range of microorganisms, including bacteria, yeasts, fungi, viruses and spores [21, 22].

The $\mathrm{pH}$ of the gel was set at 6.5 to be safe on skin. The $\mathrm{pH}$ of skin ranges from 4.5 to 6.5 [23]. The gel was formulated colorless, with a clear appearance and homogenous texture. Lemon fragrance was added to give a slight pleasant odor (Table-2). Under chemical analysis, GC confirmed the ethanol content of $80 \%$ which confirms with the set composition of the gel (Figure-1).

The results of the antibacterial activity revealed that laboratory formulation is highly effective than the studied 5 commercial brands against all tested ATCC strains with a diameter of inhibition zones (DIZ) in range of 20.1 to $21.2 \mathrm{~mm}$ as shown in Table-3 and Figure-2. Highest activity was recorded against E.coli ATCC 25922 and lowest for Pseudomonas aeruginosa ATCC 9027. The order of effectiveness of antibacterial activity was observed in following way:

\section{E.coli > Enterococcus faecalis > Staphylococcus aureus > Salmonella typhi > Pseudomonas aeruginosa.}

Among the 5 commercial brands of sanitizers tested, highest antibacterial activity was observed for CB1 hand sanitizer gel with DIZ values in range of 17.1 to $19.9 \mathrm{~mm}$ with highest activity against E.coli ATCC 25922 and lowest against Staphylococcus aureus ATCC 6538. The order of effectiveness followed a different pattern when compared with laboratory formulation.

E.coli > Salmonella typhi > Enterococcus
faecalis > Pseudomonas aeruginosa >
Staphylococcus aureus

With respect to antibacterial effectiveness of all sanitizers tested by agar well diffusion method following order of effectiveness was observed:
Laboratory formulation $>\mathrm{CB} 1>\mathrm{CB} 2>\mathrm{CB} 3>$ CB5 > CB4

A study in Central Nigeria by Oke et al., 2013 evaluated the antibacterial activity of 4 commercial brands of alcohol based hand sanitizers- Hygel, Dettol, Samclean and SKP on 5 bacterial strains by by agar diffusion assay [24]. The DIZ values were reported in range of 14.3 to $28.0 \mathrm{~mm}$ for Hygel. The remaining 3 brands of sanitizers were ineffective in demonstrating antibacterial activity against all tested bacterial strains with only Dettol showing antibacterial activity against one tested strain P.aeruginosa. This study by Oke et al., reports the inefficiency of the popular commercial brands of Ilorin, Nigeria and alerted the consumers.

The efficacy studies by MIC was determined for concentrations in the range of 100 to $1.562 \%$ by macro-dilution method. The results revealed that laboratory formulation demonstrating lowest MIC of $12.5 \%$ indicates that low concentration of the gel can still inhibit the tested ATCC bacterial strains (Table-4). On contrary commercial brands have shown an MIC of $25 \%$ for all the brands, indicating the concentration below $25 \%$ in unable to inhibit the visual bacterial growth as MIC is recorded by visual observation of end point of bacterial growth by turbidity.

MBC results obtained for laboratory formulation are in line with MIC results wherein $12.5 \%$ concentration of the gel was the lowest concentration which was bactericidal for all the tested bacterial strains. More variation was observed in results of MBC when compared with MIC for commercial brands (Table-5). CB1 sanitizer gel was found to possess bactericidal property at $100 \%$ gel concentration. The antibacterial effect declined with decrease in percentage of gel $(50 \%)$ with mild inhibitory action on the bacterial growth. This was observed in results of MIC where 50 and $25 \%$ concentration of the gel can inhibit the bacterial growth. Parallely, CB2 and CB5 sanitizer gel also demonstrated similar results with bactericidal action only at $100 \%$ concentration, and only have inhibitory effect rather than bactericidal effect at lower concentration of 50 and $25 \%$.

MBC data for the other two commercial brands- $\mathrm{CB} 3$ and $\mathrm{CB} 4$ sanitizer gels have conflicting results. Both the commercial brands are able to demonstrate bactericidal effect on only three among the five tested bacterial strains including E.coli, S.aureus and P.aeruginosa, and lack bactericidal effect against S.typhi and E.faecalis. It was also observed that only $100 \%$ concentration of the gel was able to kill the three tested bacterial strains and this concentration was unable to kill the remaining two bacterial strains. $50 \%$ and lower concentrations were inefficient to kill the bacterial strains and express only inhibitory effect as observed in MIC results. These results clearly indicate 
that selected commercial brands of hand sanitizers have very low efficacy and are unable to demonstrate the efficiency to kill the tested bacterial strains which are indicators for hand hygiene. On contrary laboratory formulated gel was very effective to inhibit and kill all tested bacterial strains at a low concentration of $25 \%$ which indicates its high efficiency.

Evaluation of antibacterial efficacy of four commercial alcohol based hand sanitizers was also studied by Oke et al., 2013 [24]. The results of MIC and MBC indicate that the tested sanitizers- Hygel, Dettol, Samclean and SKP are only bacteriostatic in nature and does not have any bactericidal effect. It was also reported that these commercial brands have MIC of $100 \%$ indicating that they are active only at $100 \%$ concentration. The results of $\mathrm{MBC}$ revealed that none of these tested brands are bactericidal even at $100 \%$ concentration. Surini et al., 2018 have tested effectiveness of hand sanitizer gel produced from salam bark extracts [25]. In their study high efficiency of the sanitizer gel was reported with a MIC of $3.12 \%$. The utilization of MIC as a standard method to evaluate the efficacy of sanitizing agents was also reported by Mazzola et al., 2009 [26]. In this study a number of alcohol based and alcohol free sanitizing agents used in hospital were evaluated for their efficacy against 6 bacterial strains from ATCC. For ethanol based sanitizing agents, the reported MIC levels which reduced bacterial count over $6 \log 10$ were in the range of 43750 to $87500 \mathrm{mg} / \mathrm{L}$.

Results for field test- hygienic hand rub test are a final indicator for efficacy of hand sanitizer. In the present study the laboratory formulated gel was highly effective with a mean cfu reduction of $99.243 \%$ demonstrated on transient flora of volunteers hand in 30 seconds (Table-6). The tested commercial brands have expressed mean cfu reduction in the range of 83.15 to $98.372 \%$. Among the five commercial brands tested, high cfu reduction was observed for CB1 hand sanitizer gel $(98.372 \%)$ followed by CB2 $(95.479 \%)$ and CB5 (94.61\%). Lowest cfu reduction was recorded for CB4 $(91 \%)$ and CB3 $(83.15 \%)$. These results demonstrate that tested commercial brands of hand sanitizers were unable to produce a cfu reduction of $99.99 \%$ which is normally claimed by almost all hand sanitizers available in market. Oke et al., 2013 also reported mean cfu reduction of 89.90 and 73.80 for two commercial brands- Hygel and Dettol which was less than $99.9 \%$ reduction printed on the labels of these products [24].

In the present study alcohol based six hand sanitizing gels were analyzed, 5 commercial sanitizing gels and one laboratory formulated gel are ethanol based and one commercial brand CB1 is based on isopropanol as active ingredient. The active ingredient alcohol has potential to denature proteins and is the main reason for its antimicrobial activity [4]. The most effective concentration of alcohols to express antimicrobial activity is $60-80 \%$. As the concentration increases above $80 \%$, it is reported that the potency of alcohol is reduced [27]. This is due to its decrease in denaturing capacity of proteins as proteins are not denatured easily in the absence of water [4]. The in vivo antimicrobial activity of alcohols has been reported in several studies. Some of the earlier reports based on quantitative studies on antibacterial handrubs established that alcohols effectively reduce bacterial counts on hands [28, 29]. Alcohols are rapidly germicidal when applied to the skin, but have no appreciable persistent (residual) activity. However, regrowth of bacteria on the skin occurs slowly after use of alcohol-based hand antiseptics, presumably because of the sub-lethal effect alcohols have on some of the skin bacteria [30].

The alcohol has in vivo activity against a number of non-enveloped viruses at a concentration of $60-90 \%$ which is generally used in alcohol-based handrubs [31-33]. In vivo studies by some of the previous studies using a fingerpad model have shown that $70 \%$ ethanol and isopropanol were more effective in reducing rotavirus titres on fingerpads than medicated or non-medicated soap [32, 34]. Another study on fingerpads for evaluation of commercial product with $70 \%$ ethanol reported 3-4 log reduction of infectivity titres of non-enveloped viruses- rotavirus, adenovirus and rhinovirus [33]. There are certain reports which indicate that depending on the concentration of alcohol, time of application and type of virus, alcohol might be ineffective against hepatitis $\mathrm{A}$ and other non-lipophilic viruses. In support to this Schurmann \& Eggers reported that the inactivation of non-enveloped viruses is influenced by temperature, the ratio of disinfectant to virus volume, and protein load [35]. In general, ethanol has greater activity against viruses than isopropanol [13]. However, further research in vitro and in vivo studies are required for both alcohol-based formulations and antimicrobial soaps to prove the minimal level of virucidal activity for preventing direct contact transmission of viruses in health-care settings.

A number of factors affect the efficacy of alcohol-based hand hygiene products, like concentration of alcohol, type of alcohol, contact time, volume used and conditions of hand when alcohol is applied wet or dry. If small volume of less than $1 \mathrm{ml}$ of alcohol is applied to hands, there is no effect and is similar to washing hands with plain soap and water [36, 37]. In another report, it was revealed that small volume of alcohol of about $1 \mathrm{ml}$ was significantly less effective than $3 \mathrm{ml}$ [38]. The ideal volume of product to apply to the hands for sanitization may vary for different formulations and is not known. In general, however, if hands feel dry after being rubbed together for less than 
10-15 seconds, it is likely that an insufficient volume of product was applied [36].

\section{Conclusion}

Based on the results obtained in the study we conclude that the laboratory formulated alcohol based gel was found to be highly effective than the five tested alcohol based sanitizers commercially available in Riyadh City in inhibiting and killing the five tested bacterial strains and has a $99.24 \%$ cfu reduction of total bacterial count on volunteer hands in 30 seconds.

\section{ACKNOWLEDGMENTS}

The authors are thankful to Management of Riyadh Municipality and Dar Al-Najat Medical Technology for providing the facilities to carry out this work.

\section{REFERENCES}

1. Rotter, M. (1999). Hand washing and hand disinfection. In: Mayhall CG, ed. Hospital epidemiology and infection control, $2^{\text {nd }}$ edition. Philadelphia, PA, Lippincott Williams \& Wilkins: 1339-1355.

2. WHO Guidelines on Hand Hygiene in Health Care. (2009). WHO Press, Geneva, Switzerland.

3. Rotter, M. L., Kampf, G., Suchomel, M., \& Kundi, M. (2007). Population kinetics of the skin flora on gloved hands following surgical hand disinfection with 3 propanol-based hand rubs: a prospective, randomized, double-blind trial. Infection Control and Hospital Epidemiology, 28:346-350.

4. Larson, E. L., \& Morton, H. E. (1991). Alcohols, In: Block SS, ed. Disinfection, sterilization and preservation, 4th edition. Philadelphia, PA, Lea \& Febiger: 191-203.

5. Sakuragi, T., Yanagisawa, K., \& Dan, K. (1995). Bactericidal activity of skin disinfectants on methicillin-resistant Staphylococcus aureus. Anesthesia and Analgesia, 81:555-558.

6. Kampf, G., Jarosch, R., \& Ruden, H. (1998). Limited effectiveness of chlorhexidine-based hand disinfectants against methicillin-resistant Staphylococcus aureus (MRSA). Journal of Hospital Infection, 38:297-303.

7. Kampf, G., Hofer, M., \& Wendt, C. (1999). Efficacy of hand disinfectants against vancomycin-resistant Enterococci in vitro. Journal of Hospital Infection, 42:143-150.

8. Platt, J., \& Bucknall, R. A. (1985). The disinfection of respiratory syncytial virus by isopropanol and a chlorhexidine-detergent handwash. Journal of Hospital Infection, 6:89-94.

9. WHO. Coronavirus Disease 2019 (COVID-19). (2020). Situation Report 55. https://www.who.int/emergencies/diseases/novelcoronavirus-2019/situation-reports
10. Centers for Disease Control and Prevention. (2020). https://www.cdc.gov/coronavirus/2019ncov/prepare/prevention.html

11. Price, P. B. (1996). New studies in surgical bacteriology and surgical technique. JAMA, 111:1993-1996.

12. Wilson, M. (2005). Microbial inhabitants of humans: their ecology and role in health and disease. New York, NY, Cambridge University Press.

13. Kampf, G., \& Kramer, A. (2004). Epidemiologic background of hand hygiene and evaluation of the most important agents for scrubs and rubs. Clinical Microbiology Review, 17:863-893.

14. Clinical Laboratory Standard Institute M02-A12. (2015). Performance Standards for Antimicrobial Disk Susceptibility Tests; Approved Standard- $12^{\text {th }}$ Edition, CLSI, Wayne, Pennsylvania, USA: 35(1).

15. Clinical Laboratory Standard Institute M07-A8. (2009). Methods for Dilution Antimicrobial Susceptibility Tests for Bacteria That Grow Aerobically; Approved Standard- $8^{\text {th }}$ Edition, CLSI, Wayne, Pennsylvania, USA: 29(2).

16. BSI Standard Publication. (2013). Chemical disinfectants and antiseptics- Hygienic handrubTest method and requirements (phase 2/step 2). BS EN 1500:2013.

17. Guide to Local Production: WHO-recommended Handrub Formulations, Revised April-2010:1-9.

18. Tentative Final Monograph for Health Care Antiseptic Drug Products. (1994). Proposed Rule Department of Health and Human Services, Food and Drug Administration. Federal Register Volume 59, Number 116, FR Doc No: 94-14503.

19. Standardization ECF. (CEN 1997). Chemical disinfectants and antiseptics - hygienic handrub test method and requirements.

20. Platt, J., \& Bucknall, R. A. (1985). The disinfection of respiratory syncytial virus by isopropanol and a chlorhexidine-detergent handwash. Journal of Hospital Infection, 6:89-94.

21. Rutala, W. A., Gergen, M. F., Weber, D. J. (1993). Sporicidal activity of chemical sterilants used in hospitals. Infect. Control Hosp. Epidemiol, 14:713-8.

22. Block, S. S. (2001). Peroxygen compounds. In: Block SS, ed. Disinfection, sterilization, and preservation. Philadelphia: Lippincott Williams \& Wilkins: 185-204.

23. Heather, A. E., \& Adam, C. W. (2012). Transdermal and Topical Drug Delivery: Principles and Practice. $1^{\text {st }}$ edition. New Jersey: Wiley: 432.

24. Oke, M. A., Bello. A. B., Odebisi, M. B., Ahmed El-Imam, A. M., \& Kazeem, M. O. (2013). Evaluation of Antibacterial Efficiacy of Some Alcohol-Based Hand Sanitizers Sold in Ilorin (North- Central Nigeria). Ife Journal of Science, 15(1), 111-117. 
25. Surini, S., Amirtha, N. I., \& Lestari, D. C. (2018). Formulation and effectiveness of a hand sanitizer gel produced using Salam bark extract. Int. J. Appl. Pharmaceutics, 10 (1), 216-220.

26. Mazzola, P. G., Jozala, A. F., de Lencastre Novaes, L. C., Moriel, P., \& Penna, T. C. V. (2009). Minimal inhibitory concentration (MIC) determination of disinfectant and/or sterilizing agents. Brazilian Journal of Pharmaceutical Sciences, 45(2), 241-248.

27. Harrington, C., \& Walker, H. (1903). The germicidal action of alcohol. Boston Medical and Surgical Journal, 148:548-552.

28. Pohle, W. D., \& Stuart, L. S. (1940). The germicidal action of cleaning agents - a study of a modification of Price's procedure. Journal of Infectious Diseases, 67:275-281.

29. Pillsbury, D. M., Livingood, C. S., Nichols, A. C. (1942). Bacterial flora of the normal skin. Archives of Dermatology, 45:61-80.

30. Lilly, H. A. Lowbury, E. J., Wilkins, M. D., \& Zaggy, A. (1979). Delayed antimicrobial effects of skin disinfection by alcohol. Journal of Hygiene (London), 82:497-500.

31. Steinmann, J., Nehrkorn, R., Meyer, A., \& Becker, K. (1995). Two in vivo protocols for testing virucidal efficacy of handwashing and hand disinfection. Zentralblatt fur Hygiene und Umweltmedizin, International Journal for Hygiene and Environmental Medicine, 196:425436.

32. Ansari, S. A., Springthorpe, V. S., Sattar, S. A., Tostowaryk, W., \& Wells, G. A. (1991). Comparison of cloth, paper, and warm air drying in eliminating viruses and bacteria from washed hands. American Journal of Infection Control, 19:243-249.

33. Sattar, S. A., Abebe, M., Bueti, A. J., Jampani, H., Newman, J., \& Hua, S. (2000). Activity of an alcohol-based hand gel against human adeno-, rhino-, and rotaviruses using the fingerpad method. Infection Control and Hospital Epidemiology, 21:516-519.

34. Ansari, S. A., Sattar, S. A., Springthorpe, V. S., Wells, G. A., \& Tostowaryk, W. (1989). In vivo protocol for testing efficacy of hand-washing agents against viruses and bacteria: experiments with rotavirus and Escherichia coli. Applied Environmental Microbiology. 55(12), 3113-3118.

35. Schurmann, W., \& Eggers, H. J. (1983). Antiviral activity of an alcoholic hand disinfectant: comparison of the in vitro suspension test with in vivo experiments on hands, and on individual fingertips. Antiviral Research. 3:25-41.

36. Marples, R. R., \& Towers, A. G. (1979). A laboratory model for the investigation of contact transfer of micro-organisms. Journal of Hygiene (London). 82:237-248.

37. Mackintosh, C. A., \& Hoffman, P. N. (1984). An extended model for transfer of micro-organisms via the hands: differences between organisms and the effect of alcohol disinfection. Journal of Hygiene (London). 92:345-355.

38. Larson, E. L., Eke, P. I., Wilder, M. P., \& Laughon, B. E. (1987). Quantity of soap as a variable in handwashing. Infection Control. 8(9), 371-375. 